\title{
OPTIMALISASI MEDIA SOSIAL FACEBOOK UNTUK MENDUKUNG PERLUASAN JARINGAN PEMASARAN BAGI KELOMPOK WANITA KREATIF (KWK) SEROJA
}

\author{
Retnowati $^{1}$, Eko Nur Wahyudi ${ }^{2}$, Sariyun Naja Anwar ${ }^{3}$, Hersatoto Listiyono ${ }^{4}$ \\ Manajemen Informatika, Fakultas Teknologi Informasi \\ Universitas Stikubank (UNISBANK) \\ Jalan Tri Lomba Juang No. 1 Mugas Semarang \\ Email Korespondensi: retnowati@edu.unisbank.ac.id
}

Received : June 14, 2020 ; Accepted : July 8, 2020 ; Published : January $1^{\text {st }}, 2021$

\begin{abstract}
Abstrak
Kelompok Wanita Kreatif (KWK) Seroja terdiri dari ibu rumah tangga, memiliki potensi yang besar untuk meningkatkan jejaring pemasaran produk, karena usaha yang dijalankan telah digeluti selama hampir 10 tahun dengan usia yang relatif produktif. Sampai saat ini anggota KWK Seroja memiliki usaha di bidang konveksi, pangan, penyewaan dan souvenir itu, tapi masih menggunakan model pemasaran tradisional seperti membuka usaha di rumah atau memasarkannya secara door to door. Pesatnya penggunaan media sosial seperti facebook dapat membantu pemasaran lebih efisien dan efektif, karena jejaring yang luas. KWK Seroja perlu dibantu melalui informasi tentang pentingnya transformasi pemasaran dari tradisional ke basis media sosial, yaitu fans page facebook yang dioptimalkan. KWK Seroja juga perlu pendampingan untuk ikut dalam pameran UMKM agar memperkuat kedudukannya di mata masyarakat. Hasil yang diperoleh adalah antusiasme yang baik dari para anggota yang mampu membuat fans page sesuai dengan produk masing-masing dan kesediaan untuk mengiktui pameran UMKM setahun sekali.
\end{abstract}

Kata Kunci: Facebook; Fans Page, Optimalisasi

\begin{abstract}
The Creative Women Group namely KWK Seroja, which consists of housewives, has great potential to increase product marketing networks, because the business it has been in has been in business for almost 10 years with a relatively productive age. Until now KWK Seroja members have businesses in the fields of convection, food, rental and souvenirs, but still use traditional marketing models such as opening a business at home or marketing it door-to-door. The rapid use of social media such as Facebook can help marketing more efficiently and effectively, due to the extensive network. KWK Seroja needs to be helped through information about the importance of marketing transformation from traditional to social media bases, namely optimized Facebook fans page. KWK Seroja also needs assistance to participate in the UMKM exhibition to strengthen its position in the eyes of the community. The results obtained were good enthusiasm from the members who were able to create a fan page in accordance with their respective products and a willingness to follow the UMKM exhibition once a year.
\end{abstract}

Keywords : Facebook; Fans Page, Optimalisation 


\section{Pendahuluan}

Era industri 4.0 adalah sebuah era yang mengubah paradigma berpikir dan bertindak pada seluruh lapisan masyarakat dan organisasi. Tatanan kehidupan bermasyarakat telah mengalami transformasi dari cara berkomunikasi, bekerja, berinteraksi satu sama lain[1]. Hal ini disebabkan oleh pemanfaatan teknologi informasi dan komunikasi termasuk media sosial yang memudahkan jejaring menjadi cepat, murah dan mudah.

Media sosial seperti halnya facebook telah berhasil membentuk jejaring sangat luas bagi manusia dalam berbagai hal, seperti berkomunikasi, berbagi foto, video, informasi dan lain sebagainya. Berdasarkan data dari berbagai sumber media, pengguna facebook di Indonesia telah mencapai sekitar 130 juta orang di tahun 2018 [2], [3]. Besarnya jejaring yang terbentuk melalui facebook seharusnya memberikan celah dan peluang bagi setiap orang yang ingin memanfaatknya untuk hal-hal positif, termasuk hal berbisnis. Foto pribadi dapat diubah menjadi foto produk sebagai promosi yang dapat dibagikan dalam jejaring yang besar. Beberapa peneliti memaparkan hasil temuannya bahwa media sosial telah diakui memiliki nilai transformasi [4]yang efektif dan memadai bahkan mengungguli pola pemasaran produk tradisional [5], memiliki kemampuan memberi peran untuk membangun image yang baik pada produknya melalui konsep branding bagi produk yang akan dipasarkan $[6]$.

Pemanfaatan media sosial facebook telah dibuktikan memberi dampak signifikan pada pemasaran suatu produk, seperti studi kasus produk Samsung [7], mampu menjangkau konsumen secara luas seperti yang dilakukan dan dibuktikan dalam penelitian perusahaan telekomunikasi di Yordania [8] dan juga Arab Saudi [9]. Fasebook juga disarankan bagi organisasi untuk memperluas jaringan pemasaran untuk memperkuat posisi dan eksistensinya di masyarakat [10]. Oleh karenanya, media sosial seperti facebook layak untuk digunakan dan dioptimalkan bagi masyarakat yang ingin memanfaatkan peluang berbisnis [11]. Kemudahan pola pemasaran menggunakan media sosial facebook perlu ditawarkan kepada masyarakat agar memberikan manfaat bagi usaha mereka. Pemberian strategi untuk optimalisasi facebook sebagai media pemasaran dan sekaligus pendampingan harus dilakukan kepada khalayak dengan pendekatan yang tepat.

Keyakinan bahwa media sosial seperti facebook dapat dimanfaatakan untuk mengoptimalkan pemasaran produk telah didukung oleh beberapa penelitian terdahulu. Sekalipun demikian, penggunakan media sosial facebook tetap memiliki sejumlah kendala yang harus dipahami, sehingga penggunaan media tersebut dapat memperkecil kegagalan pemasaran. Salah satu kendala yang harus diatas antara lain pentingnya faktor kepercayaan dari pembuat produk serta faktor strategi merangkul konsumen [12], [13]. Selain kedua hal tersebut, kendala yang harus diantisipasi adalah faktor perencanaan terhadap konten pemasaran produk [14]. Serangkaian strategi yang dapat dipertimbangkan untuk memperkuat pemasaran menggunakan facebook antara lain pembuatan fans pages, groups, video, images dan adds [15]. Dengan mempertimbangkan aspek manfaat serta kendala yang dihadapi dari penggunaan facebook sebagai sarana pemasaran, maka pemanfaatan facebook untuk pemasaran ini perlu disosialisasikan kepada khalayak yang membutuhkan dengan pendampingan yang tepat.

Di Salatiga Jawa Tengah, terdapat kelompok wanita selaku ibu rumah tangga, yang bergabung dalam wadah Kelompok Wanita Kreatif, untuk selanjutnya disingkat KWK. KWK Seroja adalah wadah organisasi para ibu rumah tangga yang memiliki misi dan visi yang sama dalam rangka mengembangkan usaha kreatif berbasis keluarga dan masyarakat. KWK Seroja secara khusus berdiri pada tahun 2016, yang memiliki 25 anggota dengan jenis usaha kreatif rumah tangga beraneka ragam. Berdasarkan observasi awal yang telah dilakukan oleh tim, dapat diketahui bahwa KWK Seroja secara individu telah memiliki produk seperti sirup 
jahe, peralatan rumah tangga dari bahan plastik limbah, konveksi dalam skala kecil, dan lain sebagainya. Sedangkan jangkauan penjualannya berada di wilayah Salatiga dan sekitarnya. Adapun media promosi yang dilakukan adalah melalui cara door to door, seperti mempromosikan melalui kelompok PKK, Dasa Wisma atau kelompok-kelompok masyarakat yang berkenan memberikan waktu bagi mereka untuk mempromosikan produknya. Cara lain adalah dengan membuka lapak di rumah atau warung sendiri atau dititipkan di toko-toko.

Peluang usaha bagi KWK Seroja cukup besar dan memberikan kemanfaatan yang memadai bagi pribadi dan keluarganya sebagai upaya untuk meningkatkan kesejahteraan, juga memberikan kontribusi positif bagi masyarakat di sekitarnya. Sekalipun demikian, salah satu kekurangan dari KWK Seroja ini adalah aspek pemasaran. Pemasaran yang dilakukan menggunakan konsep pemasaranan tradisional. Kelemahan model pemasaran yang dilakukan adalah wilayah jangkauan pasar yang sempit, waktu yang digunakan relatif banyak, tenaga yang digunakan untuk melakukannya juga harus diperhitungkan. Sedangkan keuntungan yang diperoleh seharusnya dapat ditingkatkan. Persoalan lain yang diidentifikasi adalah kurangnya pendampingan dari pihak terkait, untuk meningkatkan kemampuan KWK Seroja meningkatkan jaringan pemasarannya. Pertemuan yang dilakukan masih sebatas kepada diskusi, memberikan dorongan moral satu sama lain untuk maju. Padahal, saat ini media sosial dapat dijadikan sebagai sarana yang potensial untuk memperluas jaringan pemasaran. Selain KWK Seroja sangat berpeluang untuk menjadi embrio bisnis start up ibu-ibu rumah tangga kreatif di wilayah Salatiga, terutama Kecamatan Sidorejo.

Dengan demikian masalah yang hendak diselesaikan adalah pertama perlunya informasi tentang pentingnya transformasi pemasaran tradisional ke pemasaran berbasis media sosial facebook, kedua perlunya pelatihan cara mengoptimalkan media sosial facebook dalam pemasaran, ketiga pendampingan pemanfaatan media sosial facebook. Hal ini sesuai dengan kendala yang harus diatasi ketika sebuah organisasi atau seseorang ingin memanfaatkan media sosial facebook sebagai alat pemasarannya, seperti yang telah dijelaskan pada latar belakang, yaitu perlunya strategi untuk meningkatkan rasa percaya diri, strategi konten yang dapat menjangkau konsumen dengan baik [14], [15] dengan memadukan video, audio, image dan langkah perawatan kontennya.

\section{Metode}

Dalam rangka mencapai tujuan penyelesaian masalah, maka diperlukan acuan kerja yang dimulai dari tahap persiapan, pelaksanaan, evaluasi kerja.

Pada tahap persiapan, hal-hal yang dilaksanakan adalah sebagai berikut:

a. Penentuan Metode Kegiatan : Ceramah dan Praktik Langsung

b. Materi Pelatihan : Mengoptimalkan Facebook Sebagai Media Pemasaran

Dengan Menggunakan Konsep Fans Page

c. Target Peserta : 25 orang (seluruh anggota KWK Seroja)

d. Partisipasi Peserta

1) Setiap anggota mempersiapkan Smart Phone yang dimiliki

2) Setiap anggota mempersiapkan foto-foto produk yang akan dijadikan sebagai sarana berlatih

e. Persiapan Tim : Setiap anggota tim berbagi tugas sebagai narasumber dan pendamping pada saat praktik membuat Fans Page dilaksanakan

Tahap pelaksanaan terdiri atas beberapa kegiatan, yaitu:

a. Pre Test dan Post Test

Tujuan pemberian pre test dan post test ini adalah untuk mengetahui pemahaman peserta terhadap materi sebelum dan sesudah kegiatan pelatihan/pendampingan dilaksanakan.

b. Pendataan 
Pendataan KWK Seroja Secara Lengkap sebagai bagian dari keberlanjutan pendampingan jika diperlukan

Tujuan pendataan ini adalah untuk mengetahui secara lebih mendetail potensi KWK Seroja yang dapat dioptimalkan untuk kepentingan kelompoknya maupun tim, di masa yang akan datang

c. Pemberian Materi

Isi dari materi pertama adalah: Perkembangan Dunia Usaha, Pemanfaatan Sosial, Media Untuk Pemasaran Bagi Dunia Usaha dan Pemanfaatan Facebook Untuk Pemasaran Bagi Dunia Usaha.

Tujuan dari materi ini adalah menjelaskan alasan memanfaatkan sosial media sebagai media pemasaran dan terfokus pada salah satu sosial media Facebook.

Isi dari materi kedua ini adalah Tahap-Tahap Pembuatan Fans Page Di Dalam Facebook dan Membuat Fans Page Dengan Panduan Tim Pengabdian.

Tujuan dari pemberian materi kedua ini adalah menjelaskan tentang pembuatan Fans Page secara teori sekaligus praktik dengan menggunakan SmartPhone yang dimiliki oleh peserta KWK Seroja.

d. Evaluasi

Bentuk evaluasi yang dilakukan dengan menentukan terlebih dahulu indikator capaian dari hasil pemaparan materi, selanjutnya dilakukan pendampingan untuk pemasaran termasuk pendampingan pameran UMKM yang diadakan oleh kota dan kemudian membuat berkas publikasi dalam wujud artikel sebagai bukti pertanggungjawaban kegiatan.

Tabel 1 adalah indikator yang ditetapkan untuk mengevaluasi kegiatan. Sedangkan gambar 1 adalah diagram alur kegiatan pelaksanaan pengabdian kepada masyarakat yang dilakukan.

Tabel 1. Indikator Keberhasilan Kegiatan

\begin{tabular}{l|l|l|l}
\hline No & \multicolumn{1}{|c|}{ Kegiatan } & \multicolumn{1}{c}{ Indikator } \\
\cline { 3 - 4 } & \multicolumn{1}{c}{ Masukan } & \multicolumn{1}{c}{ Luaran } \\
\hline \hline 1 & $\begin{array}{l}\text { Pre Test dan Post Test } \\
\text { Pemahaman Tentang } \\
\text { Pentingnya Penggunaan Media } \\
\text { Sosial Untuk Marketing serta } \\
\text { Cara Membuatnya dengan FB } \\
\text { Fans Page }\end{array}$ & $\begin{array}{l}\text { Pre Test : 0\% paham } \\
\text { (dari 25 anggota) }\end{array}$ & $\begin{array}{l}\text { Post Test: 75\% } \\
\text { paham (dari 25 } \\
\text { anggota) }\end{array}$ \\
\hline 2 & $\begin{array}{l}\text { Pendataan Biodata Anggota } \\
\text { KWK Seroja }\end{array}$ & $\begin{array}{l}\text { Belum terdata, } \\
\text { Belum teranalisa } \\
\text { secara deskriptif }\end{array}$ & $\begin{array}{l}\text { Terdata, teranalisa } \\
\text { secara deskriptif }\end{array}$ \\
\hline 3 & $\begin{array}{l}\text { Ceramah dan Praktik membuat } \\
\text { FB Fans Page, dilakukan } \\
\text { langsung oleh tim sebagai } \\
\text { narasumber dan pendamping }\end{array}$ & $\begin{array}{l}\text { Jumlah FB Fans } \\
\text { Page = 0 } \\
\text { (dari 25 anggota) }\end{array}$ & $\begin{array}{l}\text { Jumlah FB Fans } \\
\text { Page = 18 }\end{array}$ \\
\hline 4 & $\begin{array}{l}\text { Keikutsertaan Dalam Pameran } \\
\text { UMKM }\end{array}$ & Belum pernah & Minimal 1 tahun 1 x \\
\hline
\end{tabular}




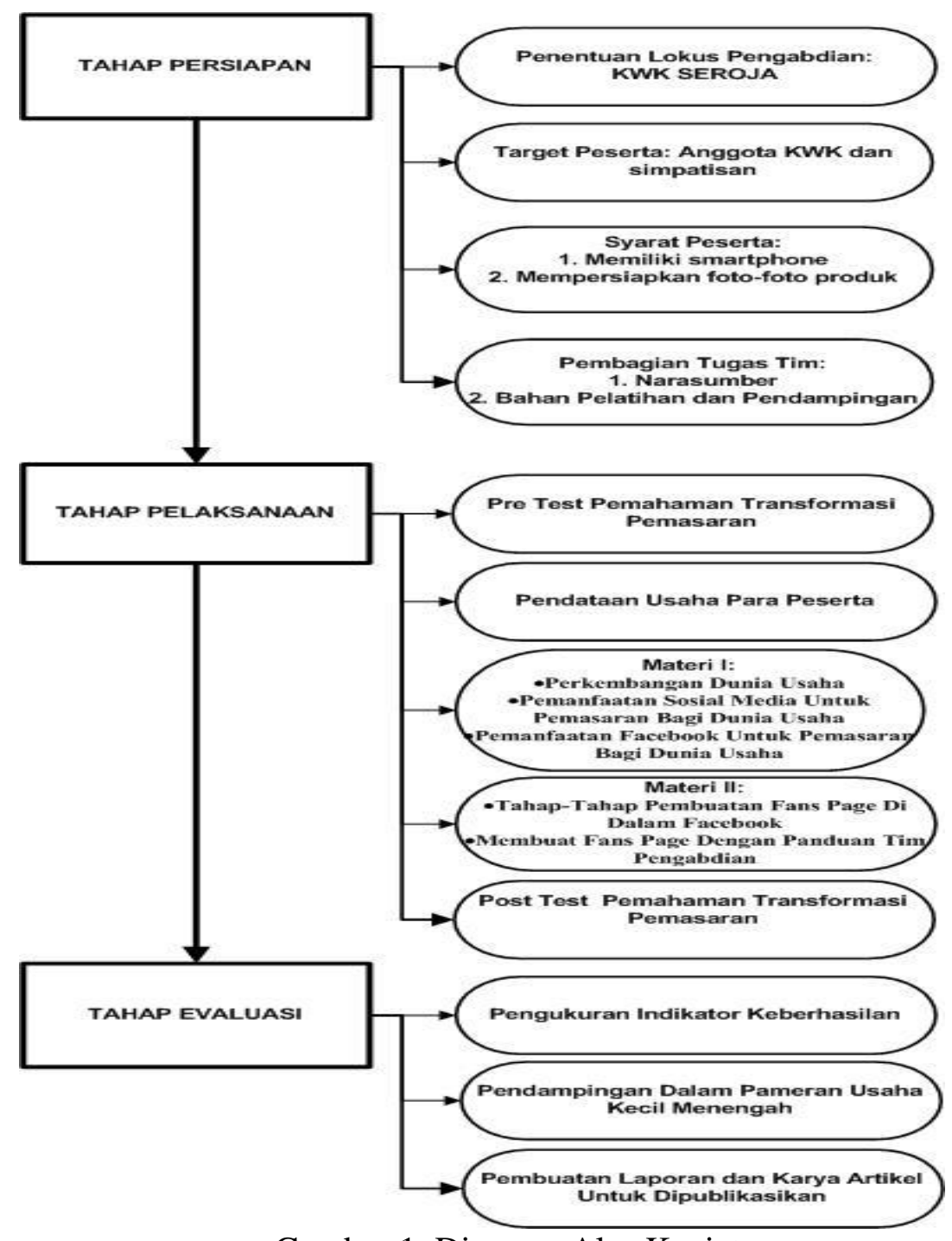

Gambar 1. Diagram Alur Kegiatan

\section{Hasil dan Pembahasan}

Transformasi pemasaran dari model pemasaran tradisional ke model pemasaran berbasis media sosial [16]-[18] harus diwacanakan dan diinformasikan kepada anggota KWK Seroja. Pemasaran menggunakan media sosial facebook tidak sulit dan dapat memberikan nilai jual yang jauh lebih baik [6], [19] bagi para ibu rumah tangga yang bergabung dalam KWK Seroja. Oleh karenanya, diperlukan analisa terhadap pemahaman para peserta terhadap pentingnya perubahan cara berpikir mereka terhadap konsep pemasaran produk yang dihasilkannya.

Hasil pre test dan post test yang dilakukan memberikan gambaran terhadap situasi kekuatan KWK Seroja. Dari 22 peserta yang terdaftar, 20 orang peserta terlibat secara aktif pada saat pre test maupun post test. Dua orang lainnnya buta huruf dan sudah cukup lanjut usia. Adapun hasil dari pre test untuk 20 orang tersebut dapat disampaikan pada tabel 2. 
Tabel 2. Indikator Keberhasilan Kegiatan

\begin{tabular}{|c|c|c|c|}
\hline \multirow[t]{2}{*}{ No } & \multirow[t]{2}{*}{ Pertanyaan } & \multicolumn{2}{|c|}{ Test } \\
\hline & & Pre Test & Post Test \\
\hline 1 & Kepemilikan smartphone & $\begin{array}{l}20 \text { orang memiliki } \\
\text { smartphone }\end{array}$ & $\begin{array}{l}20 \text { orang memiliki } \\
\text { smartphone }\end{array}$ \\
\hline 2 & Menggunakan facebook & $\begin{array}{l}20 \text { orang memiliki } \\
\text { akun FB }\end{array}$ & $\begin{array}{l}20 \text { orang memiliki } \\
\text { akun FB }\end{array}$ \\
\hline 3 & $\begin{array}{l}\text { Kegunaan facebook tidak } \\
\text { hanya untuk kegiatan sosial } \\
\text { individu, tetapi dapat } \\
\text { dioptimalkan untuk pemasaran } \\
\text { produk }\end{array}$ & $\begin{array}{l}\text { - } 18 \text { orang tidak } \\
\text { mengerti FB dapat } \\
\text { dioptimalkam } \\
\text { untuk promosi } \\
\text { produk } \\
\text { - } 2 \text { orang mengerti } \\
\text { FB dapat } \\
\text { dioptimalkam } \\
\text { untuk promosi } \\
\text { produk }\end{array}$ & $\begin{array}{l}20 \text { orang mengerti } \\
\text { FB dapat } \\
\text { dioptimalkam untuk } \\
\text { promosi produk }\end{array}$ \\
\hline 4 & Pengertian fans page & $\begin{array}{l}\text { - } 19 \text { orang tidak } \\
\text { mengerti fans page } \\
\text { - } 1 \text { orang mengerti } \\
\text { fans page }\end{array}$ & $\begin{array}{l}20 \text { orang mengerti } \\
\text { fans page }\end{array}$ \\
\hline 5 & $\begin{array}{l}\text { Tahap-tahap membuat fans } \\
\text { page }\end{array}$ & $\begin{array}{l}\text { - } 20 \text { orang tidak } \\
\text { dapat mengetahui } \\
\text { tahap-tahap } \\
\text { membuat fans page }\end{array}$ & $\begin{array}{l}20 \text { orang dapat } \\
\text { mengetahui tahap- } \\
\text { tahap membuat fans } \\
\text { page }\end{array}$ \\
\hline
\end{tabular}

Kondisi demografi dari para peserta anggota KWK Seroja dapat digambarkan bahwa $68 \%$ anggota KWK Seroja berada pada usia produktif, $91 \%$ adalah ibu rumah tangga penuh, 73\% anggotanya telah menjalankan usaha lebih dari 10 tahun secara tradisional (door to door atau di rumah). Adapun jenis usaha yang dijalankan antara lain di bidang konveksi, souvenir, pangan, dan penyewaan. Gambar 2 menjelaskan diagram pie yang menyertakan persentasi kondisi KWK Seroja. Dari fakta tersebut, KWK Seroja memiliki potensi besar yang perlu digali dan diperkuat melalui pendampingan yang tepat agar para ibu yang mayoritas ibu rumah tangga mampu meningkatkan taraf kesejahteraan keluarga sehingga dapat memperkuat perekonomian masyarakat di masa mendatang. Dengan demikian, penyelenggaran pengabdian pada masyarakat yang memberikan upaya penguatan pemasaran produk para anggota KWK merupakan salah satu solusi yang tepat.

Pemberian materi pembuatan fans page untuk mengoptimalkan pemasaran produk berbasis media sosial menjadi pilihan yang baik bagi para ibu KWK Seroja, Hal ini merujuk pada Popovic yang menyatakan bahwa penggunaan media sosial dapat menjadi alat pemasaran yang murah, mudah dan efisien, melalui penyiapan konten, pemeliharaan konten dan kecerdasan analisa pemahaman pangsa pasar yang hendak diraih, sehingga keeratan antara pengusaha dan konsumen selalu terjaga dengan baik[20]. 


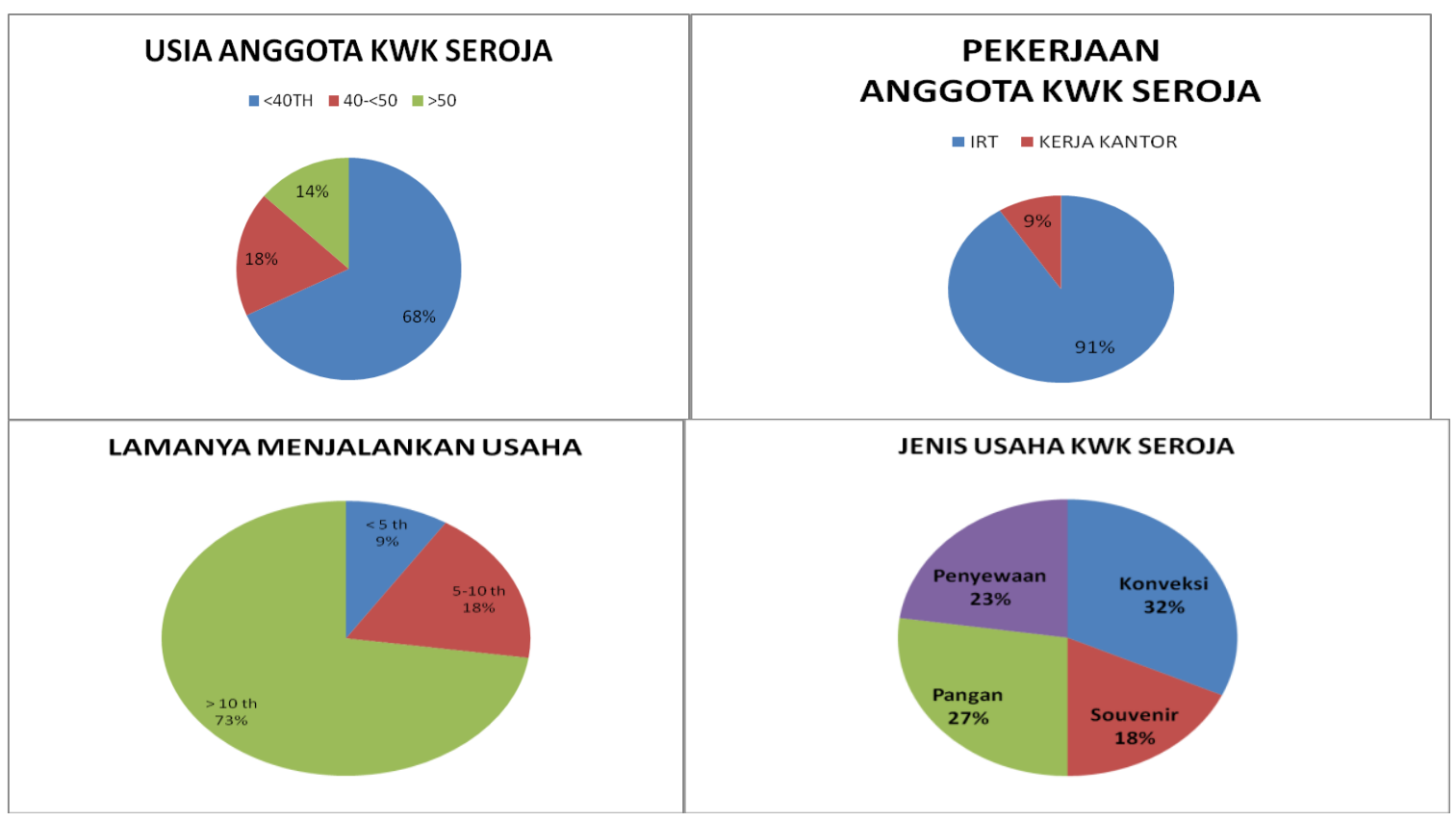

Gambar 2. Kondisi Demografi KWK Seroja

Secara umum, peserta dapat mengikuti kegiatan dan terlibat dalam pelatihan dengan baik. Dari 22 anggota terdaftar, 20 peserta mempersiapkan diri dengan baik, yaitu menggunakan smartphone, menyiapkan foto-foto produk yang akan diunggah bahkan ada yang membawa produk langsung. Dari 20 peserta tersebut ada satu orang peserta yang pernah dibuatkan fans page oleh orang lain, tetapi tidak digunakan lagi. Pada pemberian materi 1, yaitu dasar dan alasan perlunya memperluas jejaring pemasaran menggunakan sosial media, dari 20 peserta terdapat 5 orang penanya pada saat sesi diskusi, dengan pertanyaan yang kurang lebih identik. Adapun pertanyaan-pertanyaan tersebut dapat disarikan antara lain: 1) Mengapa Indonesia termasuk negara dengan pengguna Internet tertinggi, 2) Mengapa pengguna Internet lebih tertarik pada kebutuhan hidup dibandingkan pengetahuan atau keagamaan, 3) Apakah Facebook adalah satu-satunya sosial media yang dapat digunakan untuk pemasaran secara online.

Pada pemberian materi 2, yaitu pelaksanaan teknis pembuatan fans page dengan menggunakan Facebook, antusiasme peserta sangat baik. Hal ini dibuktikan dengan keinginan peserta untuk memiliki fans page sendiri. Dari 20 peserta yang telah siap membuat fans page, 20 peserta berhasil membuatnya dengan baik. Adapun nama-nama fans page yang telah dibuat adalah sebagai berikut:1) Humaira Souvenir, 2) Penganan Ibu Salimin, 3) Dania Konveksi, 4) Tas Cantik Nyonya Pitojo, 5) Aneka Snack Bu Darno, 6) Family Busana, 7) Soka Hijab, 8) Prima Busana, 9) Aneka Kebutuhan Keluarga, 10) Jajan Pasar Seroja, 11) Tas Rajut Seroja, 12) Souvenir Dari Limbah Keluarga, 13) Aneka Snack Seroja, 14) Batik Narendra, 15) Harum Konveksi \& Busana, 16) Griya Busana, 17) Toko Bunda Seroja, 18) Duta Rent House, 19) Dania Busana Adat, 20) Batik Seroja. 

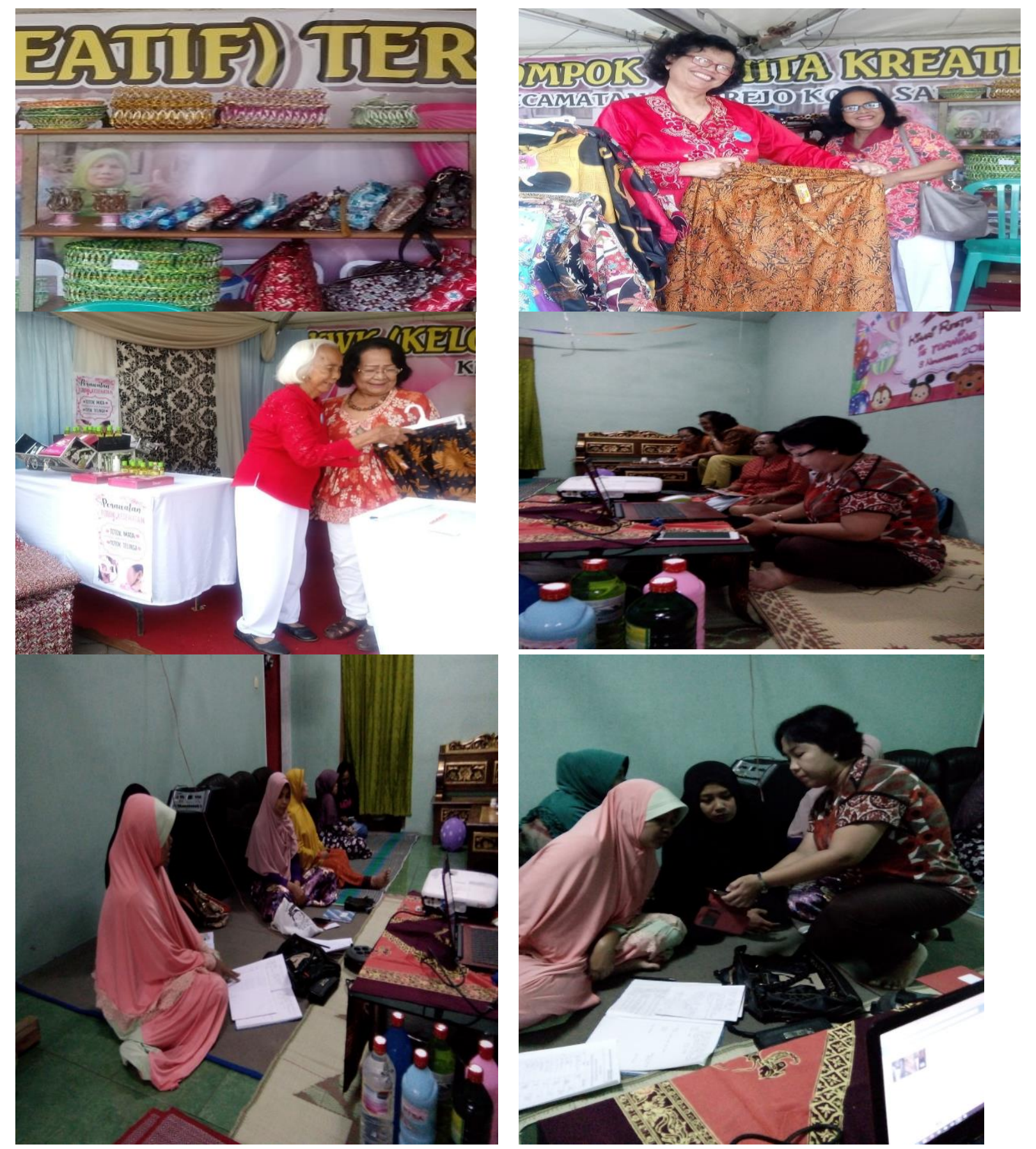

Gambar 3. Kegiatan Pendampingan dan Pameran UMKM

Hasil evaluasi terhadap kegiatan ini dapat dilakukan secara terukur karena tim telah menetapkan indikator kinerja yang telah disepakati pada saat tahap persiapan dilakukan. Tabel 3 menjelaskan tentang hasil capaian kinerja yang telah dilaksanakan oleh tim. Tabel tersebut memberikan gambaran yang nyata bahwa tujuan yang sudah ditetapkan untuk pelaksanaan pendampingan serta pelatihan untuk KWK Seroja tercapai. Dimana, tingkat pemahaman para peserta tentang facebook sebagai media pemasaran meningkat, dari awal pelaksanaan hanya 5\% yang paham tentang penggunaan facebook sebagai sarana pemasaran, berubah menjadi hampir $100 \%$. Jika selama ini belum ada pendataan dan pemetaan kekuatan anggota KWK Seroja, maka setelah pelaksaan kegiatan ini, KWK Seroja telah memiliki basis data anggota yang lebih detil, sehingga diharapkan dapat membantu para pengurus meningkatkan kapasitas mereka. Perubahan lain yang diketahui adalah bertambahnya fans 
pages dari para anggota, yang berawal hanya satu orang yang memilikinya, kini menjadi 20 buah fans pages yang dibuat oleh anggota KWK Seroja. Selanjutnya, KWK Seroja kini mengikuti kegiatan pameran produk yang diselenggarakan satu tahun sekali di tingkat kota, sementara sebelumnya para anggota belum memiliki rasa percaya diri untuk mengikutinya.

Tabel 3. Indikator Keberhasilan Kegiatan

\begin{tabular}{|c|c|c|c|c|c|}
\hline \multirow[t]{2}{*}{ No } & \multirow[t]{2}{*}{ Kegiatan } & \multicolumn{2}{|c|}{$\begin{array}{c}\text { Indikator } \\
\text { Direncanakan }\end{array}$} & \multicolumn{2}{|c|}{$\begin{array}{l}\text { Indikator } \\
\text { Dicapai }\end{array}$} \\
\hline & & Masukan & Luaran & Masukan & Luaran \\
\hline 1 & $\begin{array}{l}\text { Pre Test dan } \\
\text { Post Test } \\
\text { Pemahaman } \\
\text { Tentang } \\
\text { Pentingnya } \\
\text { Penggunaan } \\
\text { Media Sosial } \\
\text { Untuk } \\
\text { Marketing } \\
\text { serta Cara } \\
\text { Membuatnya } \\
\text { dengan FB } \\
\text { Fans Page }\end{array}$ & $\begin{array}{l}\text { Pre Test : } 0 \% \\
\text { paham } \\
\text { (dari } 25 \\
\text { anggota) }\end{array}$ & $\begin{array}{l}\text { Post Test: } \\
75 \% \text { paham } \\
\text { (dari } 25 \\
\text { anggota) }\end{array}$ & $\begin{array}{l}\text { Rerata Pre } \\
\text { Test : } 4,55 \% \\
\text { paham (dari } \\
22 \text { orang } \\
\text { anggota) }\end{array}$ & $\begin{array}{l}\text { Post } \\
\text { Test:95,45\% } \\
\text { paham (dari } 22 \\
\text { anggota) }\end{array}$ \\
\hline 2 & $\begin{array}{l}\text { Pendataan } \\
\text { Biodata } \\
\text { Anggota KWK } \\
\text { Seroja }\end{array}$ & $\begin{array}{l}\text { Belum } \\
\text { terdata, } \\
\text { Belum } \\
\text { teranalisa } \\
\text { secara } \\
\text { deskriptif } \\
\end{array}$ & $\begin{array}{l}\text { Terdata, } \\
\text { teranalisa } \\
\text { secara } \\
\text { deskriptif }\end{array}$ & $\begin{array}{l}\text { Belum } \\
\text { terdata, } \\
\text { Belum } \\
\text { teranalisa } \\
\text { secara } \\
\text { deskriptif } \\
\end{array}$ & $\begin{array}{l}\text { Terdata, } \\
\text { teranalisa } \\
\text { secara } \\
\text { deskriptif }\end{array}$ \\
\hline 3 & $\begin{array}{l}\text { Ceramah dan } \\
\text { Praktik } \\
\text { membuat FB } \\
\text { Fans Page, } \\
\text { dilakukan } \\
\text { langsung oleh } \\
\text { tim sebagai } \\
\text { narasumber } \\
\text { dan } \\
\text { pendamping }\end{array}$ & $\begin{array}{l}\text { Jumlah FB } \\
\text { Fans Page = } \\
0 \\
\text { (dari } 25 \\
\text { anggota) }\end{array}$ & $\begin{array}{l}\text { Jumlah FB } \\
\text { Fans Page = } \\
18\end{array}$ & $\begin{array}{l}\text { Jumlah FB } \\
\text { Fans Page = } \\
1\end{array}$ & $\begin{array}{l}\text { Jumlah FB } \\
\text { Fans Page }=20\end{array}$ \\
\hline 4 & $\begin{array}{l}\text { Keikutsertaan } \\
\text { Dalam } \\
\text { Pameran } \\
\text { UMKM }\end{array}$ & $\begin{array}{l}\text { Belum } \\
\text { pernah }\end{array}$ & $\begin{array}{l}\text { Minimal } 1 \\
\text { tahun } 1 \mathrm{x}\end{array}$ & $\begin{array}{l}\text { Belum } \\
\text { pernah }\end{array}$ & $\begin{array}{l}1 \times \text { dalam satu } \\
\text { tahun }\end{array}$ \\
\hline
\end{tabular}

\section{Kesimpulan}

Dari kegiatan pelatihan yang telah dilakukan oleh tim Pengabdian Kepada Masyarakat UNISBANK maka dapat ditarik beberapa kesimpulan bahwa :

1) Anggota KWK Seroja dapat mengetahui bahwa Facebook dapat dimanfaatkan untuk pengembangan pemasaran produknya 
2) Anggota KWK Seroja dapat belajar membuat Fans Page Facebook untuk mengembangkan pemasaran produknya secara online

3) Anggota KWK Seroja berhasil memiliki Fans Page Facebook sebanyak 20 buah untuk 20 anggota dari 22 anggota yang terdaftar

\section{Daftar Pustaka}

[1] M. Xu, J. M. David, and S. H. Kim, "The Fourth Industrial Revolution : Opportunities and Challenges," Int. J. Financ. Res., vol. 9, no. 2, pp. 90-95, 2018.

[2] R. C. Septania, "Indonesia, Pengguna Facebook Terbanyak ke-4 di Dunia," kompas.com, $2018 . \quad$ [Online]. Available: https://tekno.kompas.com/read/2018/03/02/08181617/indonesia-pengguna-facebookterbanyak-ke-4-di-dunia. [Accessed: 15-Dec-2018].

[3] F. Mardiyah, "Pengguna Media Sosial di Indonesia Tahun 2018," Tempo Institute, 2018. [Online]. Available: https://tempo-institute.org/berita/persentase-penggunamedia-sosial/. [Accessed: 23-Dec-2018].

[4] S. Aral, C. Dellarocas, and D. Godes, "Introduction to the Special Issue Social Media and Business Transformation: A Framework for Research," Inf. Syst. Res. Vol., vol. 24, no. 1, pp. 3-13, 2013.

[5] I. Oyza and A. Edwin, "Effectiveness of Social Media Networks as a Strategic Tool for Organizational Journal of Internet Banking and Commerce Effectiveness of Social Media Networks as a Strategic Tool for Organizational Marketing Management," $J$. Internet Bank. Commer., vol. 006, no. S2, 2015.

[6] G. Tsimonis and S. Dimitriadis, "Brand Strategies in Social Media Marketing Intelligence \& Planning Article information:," Mark. Intell. Plan., vol. 32, no. 3, pp. 328-344, 2014.

[7] W. N. Iblasi, D. M. K. Bader, and S. A. Al-qreini, "The Impact of Social Media as a Marketing Tool on Purchasing Decisions ( Case Study on SAMSUNG for Electrical Home Appliances )," Int. J. Manag. Stud. Res., vol. 4, no. 1, pp. 14-28, 2016.

[8] L. Al-Mu'ani, S. Saydam, and C. Çalicioğlu, "Facebook as a Marketing Communications Tool - Facebook Official Pages Content Analysis for Jordanian Telecommunications Companies in the Mobile Operators Sector," Int. J. Bus. Soc. Sci., vol. 5, no. 4, pp. 205-211, 2014.

[9] H. AL-Ghamdi, N. Al-Hadban, T. Al-Hassoun, and R. Hamdi, "The Effectiveness of Facebook as a Marketing Tool (Saudi Arabia case study)," Int. J. Manag. Inf. Technol., vol. 10, no. 2, pp. 1815-1827, 2014.

[10] R. R. Ramsaran-fowdar and S. Fowdar, "The Implications of Facebook Marketing for Organizations," Contemp. Manag. Res., vol. 9, no. 1, pp. 73-84, 2013.

[11] R. Ray, The facebook: Guide to Small Business Marketing. Indianapolis, Indiana: John Wiley \& Sons, Inc., 2013.

[12] I.-H. Bae and M. F. Y. Zamrudi, "Challenge Of Social Media Marketing \& Effective Strategies To Engage More Customers: Selected Retailer Case Study," Int. J. Bus. Soc., vol. 19, no. 3, pp. 851-869, 2018.

[13] E. Constantinides, "CSocial Media Marketing: Challenges and Opportunities in the Web 2.0 Marketplace," in Consumer Information Systems and Relationship Management: Design, Implementation, and Use, no. January 2013, Hersey, USA: Business Science Reference (an, 2013.

[14] N. Premanandan, "Here are the Top 4 Facebook Marketing Problems and How to Solve Them," Neal Schaffer .com, 2016. [Online]. Available: https://nealschaffer.com/top-4-facebook-marketing-problems-2017-solve/. [Accessed: 02-Jun-2019]. 
[15] N. Premanandan, "Challenges Faced in Marketing on Facebook _ SMhack," The SMhack Pyramid Hack, 2016. [Online]. Available: https://smhack.io/blog/facebookmarketing-challenges/. [Accessed: 03-Jun-2019].

[16] A. Van Looy, Social Media Management: Technologies and Strategies for Creating Business Value. London: Springer, 2016.

[17] A. Macarthy, 500 social media marketing tips essential advice, hints and strategy for business Facebook, Twitter, Pinterest, Google+, YouTube, Instagram, Linkedin, and more by Macarthy, Andrew (z-lib. Macarthy, Andrew, 2017.

[18] K. A. Quesenberry, Social Media S T R AT E GY: Marketing, Advertising, And Public Relations In The Consumer Revolution. Lahham, Maryland: Rowman \& Littlefield, 2019.

[19] L. Coles, Marketing with Social Media: 10 Easy Steps to Success for Business. Singapore: Wiley, 2015.

[20] K. Popovic, Satellite Marketing Using Social Media to Create Engangement. New York: CRC Press, 2016. 
Retnowati, Eko Nur Wahyudi , Sariyun Naja Anwar, Hersatoto Listiyono 